\title{
Uma sociologia das políticas de waterfront regeneration no Brasil: análise de três casos emblemáticos
}

Recebido: 04.08.20 Aprovado: 26.01 .21
Luciano Fedozzi (https://orcid.org/0000-0003-2066-1677), Departamento de Sociologia e do Programa de Pós-Graduação em Sociologia da Universidade Federal do Rio Grande do Sul (UFRGS), Porto Alegre, RS, Brasil'.

Mariana Vivian (https://orcid.org/0000-0001-5687-782X), Instituto Nacional de Ciência e Tecnologia (INCT) do Observatório das Metrópoles, Porto Alegre, RS, Brasil".
Resumo: Este artigo discute o tema das políticas de waterfront regeneration (WR) no Brasil. Especificamente, propõe uma sociologia política dos processos institucionais de produção de tais intervenções através da análise dos casos dos projetos Porto Maravilha, no Rio de Janeiro (RJ), do Cais Mauá, em Porto Alegre (RS) e do Porto Novo e Novo Recife, em Recife (PE). Para tanto, articula uma leitura teórica de diferentes abordagens direcionadas aos fenômenos do político e do urbano a uma pesquisa empírica qualitativa de estudo de casos múltiplos baseado em análises documentais e entrevistas. Ao final, propõe um modelo analítico para interpretação dos casos com base na síntese teórica desenvolvida e, especialmente, na perspectiva neoinstitucionalista, e apresenta um enquadramento possível de leitura dos processos de produção de tais políticas no Brasil.

Palavras-chave: Waterfront regeneration. Sociologia política. Urbanismo. Neoinstitucionalismo. Casos múltiplos.

\section{A sociology of waterfront regeneration policies in Brazil: analysis of three emblematic cases}

Abstract: This article discusses the issue of the waterfront regeneration (WR) policies in Brazil. Specifically, it proposes a political sociology of the institutional processes of production of such interventions through the analysis of the cases of the projects Porto Maravilha, in Rio de Janeiro (RJ), Cais Mauá, in Porto Alegre (RS), and Porto Novo and Novo Recife, in Recife (PE). For this purpose, it articulates a theoretical reading of different approaches directed at the phenomena of the political and the urban to a qualitative empirical research of multiple case study based on document analysis and interviews. At the end, it proposes an analytical model for the interpretation of the cases based on the theoretical synthesis developed and, especially, on the neo-institutionalist perspective, and presents a possible framework for reading the processes of production of such policies in Brazil.

Keywords: Waterfront regeneration. Political Sociology. Urbanism. Neo-institutionalism. Multiple cases.

\author{
I. Luciano Fedozzi \\ é professor do \\ Departamento \\ de Sociologia e \\ do Programa de \\ Pós-Graduação em \\ Sociologia da UFRGS, \\ pesquisador do \\ INCT Observatório \\ das Metrópoles. \\ <lucianofedozzi@ \\ gmail.com>. \\ II. Mariana Vivian é \\ mestre em sociologia \\ pelo Programa de \\ Pós-Graduação em \\ Sociologia da UFRGS, \\ pesquisadora do \\ INCT Observatório \\ das Metrópoles. \\ <marianavivian@live. \\ com>.
}




\section{Introdução}

1. O artigo extrai elementos de dissertação de mestrado defendida junto ao Programa de Pós-Graduação em Sociologia da Universidade Federal do Rio Grande do Sul (PPGS/UFRGS). Agradecemos o apoio prestado pela Coordenação de Aperfeiçoamento de Pessoal de Nível Superior (Capes) durante este período.

2. Para a realização das entrevistas, buscou-se elencar, prioritariamente, representantes do Estado, em suas diferentes esferas e níveis, e dos grupos consorciais empresariais envolvidos mais diretamente com as intervenções projetadas.

Foram também selecionados atores civis que tiveram um grau significativo de participação nos processos em estudo, como, por exemplo, representantes de movimentos de contestação local aos projetos. Elaborados com o fim de verificar indicadores específicos do modelo de análise, os roteiros de entrevistas adotaram três modelos distintos: um a ser aplicado com representantes do segmento governamental e legislativo; um a
A pesar de ainda pouco discutidas no Brasil, as políticas de waterfront regeneration (doravante WR) representam um fenômeno contemporâneo presente em inúmeras cidades do mundo. Direcionadas aos espaços de orla urbana, como cais e portos em desuso, tais políticas se apresentam como resposta a problemas urbanos em contextos diversos e ocupam hoje um espaço de relevo nas agendas e demandas de diferentes atores nas grandes e médias cidades. No Brasil, as últimas décadas testemunharam a emergência e difusão dessas propostas interventivas de norte a sul, e o tema ganhou destaque especialmente com os projetos de transformação das frentes d'água do Rio de Janeiro, Porto Alegre e Recife.

Nesse contexto, diferentemente dos estudos centrados na análise urbanística do desenho e/ou dos impactos urbanos representados pelos projetos de WR, o presente trabalho ${ }^{1}$ objetiva conhecer como são produzidos os processos institucionais que viabilizam, ou buscam viabilizar, a implementação deste tipo de política urbana no país. Como se verá, a adoção de políticas de WR no Brasil exemplificam não apenas a reverberação de políticas urbanas globais no território brasileiro, mas também a relevância da dimensão política necessária à produção de tais intervenções. Nesse sentido, embora os três casos estudados possam comportar particularidades urbanísticas e jurídicas que os distanciem em certa medida, faz-se necessário investigar se eles representam um mesmo padrão de construção institucional frente a dilemas urbanos e sociais mais amplos presentes nas cidades portuárias do país no século XXI. Eis o problema central que orienta a investigação.

A pesquisa empírica adotou a estratégia do estudo de casos múltiplos (Yin, 2001), buscando conhecer em detalhe os processos de produção e viabilização dos projetos "Porto Maravilha", no Rio de Janeiro (RJ), "Viva Cais Mauá", em Porto Alegre (RS), e "Porto Novo" e "Novo Recife", em Recife (PE). Para tal, os dados coletados e produzidos envolveram, principalmente, o levantamento documental, que reuniu e analisou documentos e registros oficiais relativos aos respectivos processos de transformação urbana, e a realização de entrevistas semi-estruturadas com os principais agentes partícipes em cada um dos três casos².Para a análise sociológica, um modelo analítico foi elaborado, tendo como base a síntese de uma leitura teórica de diferentes abordagens direcionadas aos fenômenos do político e do urbano, especialmente da abordagem neoinstitucional histórica. Centrado na noção de processo institucional, entendido como o período e o conjunto de relações que visam à produção de um resultado sociopolítico - neste caso, a implementação de uma política urbana -, o modelo distingue, como dimensões de análise, os atores 
implicados, os procedimentos adotados, os recursos mobilizados, os arranjos institucionais criados e o contexto sócio-histórico incidente.

O artigo se divide em quatro sessões principais. A primeira discute o tema das políticas de transformações urbanas denominadas "revitalizações urbanas", e, mais especificamente, aborda as políticas de WR como fenômeno sociológico contemporâneo de abrangência global, com reflexos nas cidades brasileiras. A sessão seguinte explora três casos, nas cidades do Rio de Janeiro, Porto Alegre e Recife, em que a discussão de tais políticas adquiriu um caráter mais sólido e emblemático. $\mathrm{Na}$ sequência são apresentadas algumas das abordagens teóricas existentes sobre a política urbana no campo das ciências sociais, com ênfase nas perspectivas neoinstitucionalistas que visam à explicação das dinâmicas políticas locais. Ao final, sugere-se uma sociologia política de tais intervenções urbanas, em que o modelo de análise formulado com base na síntese teórica é apresentado em maior detalhe e aplicado aos casos, produzindo enquadramentos que, argumenta-se, podem contribuir para uma melhor compreensão acerca de como políticas de transformação urbana ganham corpo no Brasil.

\section{"Revitalizações urbanas" e as políticas de waterfront regeneration}

As assim chamadas "revitalizações urbanas" podem ser entendidas como políticas de intervenção e transformação do espaço que aparecem, em primeiro lugar, como resposta à imagem de degradação e esvaziamento associada a certos territórios nas cidades, especialmente aos centros históricos urbanos. Visando promover a renovação ou a modificação dos usos que caracterizavam anteriormente estes espaços, as políticas de "revitalização urbana" traduzem um investimento público ou privado em áreas delimitadas da urbe voltadas à recuperação ou criação de centralidades urbanas em diferentes escalas. A partir de tais transformações, novas configurações - paisagísticas, econômicas, sociais, jurídicas, políticas, entre outras - são desencadeadas junto ao território alvo das intervenções. Se antes tais políticas eram voltadas prioritariamente a pequenas intervenções no patrimônio das cidades, contemporaneamente passaram a manifestar-se em impactantes transformações nas funções, no uso e no valor do solo urbano, como exemplificam os chamados Grandes Projetos Urbanos (Ribeiro, 2018).

Apesar de sua disseminada aplicação como política urbana contemporânea, o tema das "revitalizações urbanas" mostra-se bastante controverso no debate público, provocando uma variedade de análises, disposições e posicionamentos. Em pri- ser aplicado com representantes do segmento privado/ empresarial; e um a ser aplicado com o segmento civil. 
meiro lugar, merecem destaque as análises que colocam as "revitalizações" como produtos centrais de um novo urbanismo, ou de um novo modelo de planejamento urbano, em que a cidade passa a ser vista e pensada a partir de perspectivas que confrontariam a ideia do planejamento holístico e racional das décadas anteriores (Arantes, 2002). As abordagens críticas que tratam do urbanismo contemporâneo como ruptura em relação ao planejamento clássico frequentemente associam suas análises aos debates em torno dos paradigmas da "competitividade urbana", do "city marketing" e do "empreendedorismo urbano" (Garcia, 1997; Vainer, 2002; Harvey, 2005). Nesse último caso, as revitalizações em forma de grandes projetos urbanos expressariam uma "nova ordem urbana" marcada pelas transformações econômicas, políticas e sociais do capitalismo contemporâneo que repercutem na produção desigual do espaço urbano (Gonçalves, 2013; Ribeiro, 2018). Desta forma, as "revitalizações" são entendidas como projetos pontuais de intervenção urbana multidimensional que operam como recursos para os municípios adentrarem a concorrência global intercidades e, com isso, atraírem investimentos. Para tanto, estratégias de transformação por meio de políticas de gentrification seriam necessárias e, em razão disso, o debate das "revitalizações urbanas" também é frequentemente associado às discussões sobre o tema da gentrificação (Smith, 2006).

No outro extremo, análises entusiastas das "revitalizações" veem nessas políticas uma solução para um conjunto de problemas que as cidades contemporâneas enfrentam (Roberts, 2000). Transformações deste tipo são entendidas como o resultado da inter-relação entre inúmeras fontes de influência, como as forças externas à cidade que ditam uma necessidade de mudança e adaptação, e as pressões internas que podem levar ao seu crescimento ou declínio.

Dentre as experiências de intervenção recentes, as "revitalizações" de áreas e regiões portuárias assumem certa centralidade, na medida em que se referem a territórios que, por força de transformações generalizadas no sistema global de trocas marítimas, passaram por processos similares de reestruturação. Em muitos casos, tais espaços deixaram de exercer suas funções portuárias em razão de sua própria obsolescência frente a novas necessidades infraestruturais decorrentes do desenvolvimento das novas tecnologias de transporte marítimo, a partir de meados do século XX (Hoyle, 2000). Nesse contexto, os projetos e as políticas de WR emergem e parecem adquirir relativa aceitação por todo o globo, especialmente na medida em que ancoradas em um discurso que afirma conferir a esses espaços nova vitalidade.

Os processos de WR tiveram início no contexto norte-americano da década de 1960 e, a partir de então, foram constituindo-se como fenômeno mundial. Os exemplos do Fisherman's Wharf, em São Francisco, o Waterfront de Seattle, e a 
construção da Opera House, em Sidney, são considerados pioneiros, todos iniciados ao final da década de 1950. No entanto, foi apenas com os casos de Baltimore e Boston que tais políticas adquiriram maior relevo. Na Europa, o caso das Docklands de Londres partiu destas inspirações para transformar sua área portuária em um distrito residencial e empresarial. A partir do caso de Londres, uma série de outros projetos despontou no continente europeu. São exemplos o Port Vell, em Barcelona; a instalação do Guggenheim Museum, na região de Abandoibarra, em Bilbao; a transformação do Kop Van Zuid, em Roterdã; e o caso de Gênova, com o famoso Porto Ântico. Estes casos influenciaram fortemente a adoção deste tipo de transformação em locais periféricos da globalização, como exemplificam os icônicos casos de Buenos Aires e o Puerto Madero e o Victoria \& Alfred Waterfront da Cidade do Cabo.

Essas intervenções apresentam padrões similares no tocante à transformação física dos espaços portuários, que passam a abrigar complexos com uma variedade de atrativos, como shoppings centers, museus, lojas, centros de eventos, bares e restaurantes, casas de festas e shows, e até mesmo equipamentos mais espetaculares, tais como aquários, elevadores panorâmicos, cassinos, entre outros. Além disso, empreendimentos habitacionais e empresariais também aparecem em alguns desses projetos.

Os objetivos associados à produção de tais transformações são, em sua maioria, voltados à reconfiguração de um papel estratégico dos espaços selecionados, que devem se adaptar às demandas do mercado imobiliário e financeiro, assim como às novas demandas urbanas de lazer, entretenimento e turismo, atraindo investimentos para as cidades que, conforme alguns analistas, criariam nelas vantagens comparativas. Para tanto, faz-se necessária a mobilização de múltiplos instrumentos e diversos atores, além de diferentes tipos de capitais e recursos (Bassett, Griffiths \& Smith, 2002).

\section{Três casos brasileiros:}

\section{Rio de Janeiro, Porto Alegre e Recife}

No Brasil, as experiências de WR obtiveram forte repercussão, especialmente a partir de fins do século XX e início dos anos 2000, gerando discussões e polêmicas em diversas cidades portuárias. A primeira experiência nacional ocorreu em Belém, com a implementação do Complexo Turístico e Cultural Estação das Docas, no ano de 2000. Além deste, três casos exemplares passaram a ocupar a agenda de debates das cidades do Rio de Janeiro, Porto Alegre e Recife, a partir da década de 1980. 


\section{Rio de Janeiro}

No Rio de Janeiro, parte de sua zona portuária - constituída pelos bairros Saúde, Gamboa e Santo Cristo - foi alvo de uma política de intervenção de grande magnitude. Lançado no ano de 2009 pela administração municipal recém-eleita (prefeito Eduardo Paes, PMDB), o projeto "Porto Maravilha" avançou em um contexto de alinhamento político interfederativo e de preparo da cidade para sediar os Jogos Olímpicos de 2016, deixando para trás um histórico de sistemáticas propostas de transformação da região portuária.

Para o lançamento da proposta, uma série de medidas políticas foram postas em prática, especialmente a partir da deflagração do período eleitoral na cidade do Rio de Janeiro no ano de 2008. Neste momento, o Procedimento de Manifestação de Interesse (PMI) iniciado pelo executivo municipal, em 2006, em que empresas privadas foram convocadas a realizar estudos e estabelecer propostas de intervenção na região portuária, adquiriu especial relevância (Rio de Janeiro, 2006). Tão logo empossado, o novo prefeito Eduardo Paes (PMDB) buscou estabelecer diálogo com os governos estadual, de Sérgio Cabral (PMDB), e federal, de Lula (PT), ao mesmo tempo em que formava uma equipe municipal dedicada a levar adiante as propostas de transformações na área do porto (Rio de Janeiro, 2009a), tendo como ponto

3. Acerca das proposições formuladas por ocasião do PMI, ver o relatório publicado pelo Grupo de Trabalho municipal "GT Portuária", em Rio de Janeiro (2008).

4. A esse respeito, ver Rio de Janeiro (2009b; 2009c; 2009d; 2010). de partida as proposições privadas para o espaço construídas por ocasião do $\mathrm{PMI}^{3}$.

Formalmente, a política foi viabilizada através de uma Operação Urbana Consorciada (OUC), instrumento complexo e bastante polêmico previsto no Estatuto da Cidade (Brasil, 2001), abrangendo uma área de aproximadamente cinco milhões de metros quadrados. Nessa operação, as obras e alguns serviços da região foram delegados à iniciativa privada, por meio da celebração de uma Parceria Público-Privada (PPP), de duração de pelo menos 15 anos, em que figuram como partes, de um lado, o Consórcio Porto Novo - composto pelas empresas Odebrecht, OAS e Carioca Engenharia - e, do outro lado, a Companhia de Desenvolvimento Urbano da Região Portuária do Rio de Janeiro (CDURP) - empresa pública de capital misto criada para o fim de gerir e fiscalizar a OUC4.

Orçada em cerca de oito bilhões de reais, a intervenção logrou viabilidade financeira a partir da emissão de Certificados de Potencial Adicional de Construção ('s) na região pela Prefeitura e consolidou-se a partir da venda da totalidade dos certificados emitidos. Em um leilão de lote único, o Fundo de Investimentos Imobiliários Porto Maravilha (FIIPM), controlado pela Caixa Econômica Federal (CEF), adquiriu os 's e selou o direito prioritário de compra de alguns terrenos públicos localizados na região, ao passo que o Fundo de Investimentos Imobiliários da Região Portuária 
(FIIRP), controlado pela CDURP, adquiriu a garantia de que contaria com o montante de recursos necessários para a operação.

As transformações na região portuária envolveram um conjunto de obras de infraestrutura com o objetivo de implantar um novo padrão urbano naquele espaço urbano, assim como a instalação de equipamentos voltados ao lazer, à cultura, ao comércio e ao turismo. Além disso, a operação também abriu espaço para a instalação de uma grande quantidade de empreendimentos imobiliários na área, fossem estes voltados à absorção da demanda por espaços comerciais e de escritórios na região central da cidade ou à produção de habitação de diversos padrões.

\section{Porto Alegre}

Em Porto Alegre, o projeto de "revitalização" envolvendo o seu Cais Mauá, espaço localizado no Centro Histórico e relevante no imaginário e na realidade sociourbana da cidade, teve início oficial em $2010^{5}$. Nesse ano, o governo do Estado do Rio Grande do Sul (Yeda Crusius, PSDB) lançou certame licitatório visando à sua transformação em um complexo de turismo, lazer e negócios. O edital previu a celebração de Contrato de Arrendamento da área com o grupo empresarial vencedor da licitação (Rio Grande do Sul, 2010) ${ }^{6}$.

A trajetória de seu processo institucional, contudo, remonta a períodos anteriores. No ano de 2007, por exemplo, uma Manifestação de Interesse foi lançada visando à recepção de propostas de investidores privados para a área (Rio Grande do Sul, 2007). A partir do que fora proposto, uma Comissão Técnica, formada por membros dos poderes executivos estadual e municipal, passou a elaborar o conjunto de diretrizes que fundamentariam a "revitalização"7. A mesma Comissão Técnica também elaborou projeto de lei trazendo novos regimes urbanísticos para a área e discutindo seus usos possíveis (Porto Alegre, 2010). Essa coordenação entre os níveis estadual e municipal de governo foi essencial para a construção do projeto, assim como a desvinculação jurídico-urbanística do espaço do Cais Mauá de seu entorno para fins de intervenção urbana com investimentos públicos e privados.

A partir de tais marcos, fez-se possível a deflagração do processo de "revitalização" do Cais Mauá, prevendo-se a construção e a implantação no local de um shopping center, estabelecimentos comerciais, culturais e gastronômicos, centros de eventos, hotéis, torres de escritórios e estacionamentos. Em uma época em que se reafirmava uma ideia de "Porto Alegre do futuro", a transformação do Cais do Porto aparecia como política "necessária" para a cidade que viria a sediar a Copa do Mundo de 2014 e que queria ver seu Centro Histórico reabilitado.

\author{
5. Assim como no \\ caso do Rio de \\ Janeiro, contudo, \\ em Porto Alegre o \\ Cais Mauá foi alvo de \\ diversas propostas \\ de intervenção ao \\ longo de sua história \\ especialmente a \\ partir de fins da \\ década 1980.
}

6. O grupo vencedor, único concorrente, foi o consórcio de empresas denominado Porto Cais Mauá do Brasil S.A., composto pela brasileira Contern, braço da construção civil do grupo brasileiro Bertin, e mais quatro empresas espanholas, com a arquitetura do projeto ficando a cargo dos escritórios de Jaime Lerner e do catalão Femín Vázquez (Governo do Estado do Rio Grande do Sul, 2010).

7. Nessa época, representavam os governos do estado e de Porto Alegre respectivamente Yeda Crusius (PSDB) e José Fogaça (PPS e depois PMDB). 
Contudo, apesar de todos os esforços empreendidos para a sua implantação, em especial pelas sucessivas administrações públicas estaduais e municipais, a proposta "Viva Cais Mauá" foi marcada por uma série de questionamentos de órgãos jurídicos e de controle, bem como por organizações civis. Por fim, os limites financeiros do consórcio para realizar os investimentos previstos levaram à rescisão do contrato pelo governo do estado em 2019. Em 2020, foi lançado chamamento para a desestatização do espaço do cais, visando à venda da área.

Recife

Em Recife, por sua vez, dois espaços de localização privilegiada e estratégica na frente d'água, relacionados às atividades portuárias de troca, armazenamento e circulação de pessoas e mercadorias, foram objetos de projetos específicos de "revitalização". De um lado, parte da área portuária da cidade que deixou de exercer suas atividades operacionais, situada no Bairro do Recife e no Bairro de São José, seria transformada pelo projeto "Porto Novo", e, de outro lado, o Cais José Estelita, localizado entre os bairros de Boa Viagem e Recife Antigo e em frente à Bacia do Pina, seria alvo do projeto "Novo Recife".

As origens da discussão de uma possível transformação de ambas as áreas remontam ao início dos anos 2000, quando se discutia interfederativamente o famoso e ambicioso "Projeto Recife-Olinda" - proposta que veiculava a realização de uma grande operação urbana envolvendo 470 hectares de área de ambas as cidades, com a reconfiguração de suas linhas de frente d'água (Brasil, 2005; 2006). Entre os anos de 2007 e 2008, contudo, dois fatos geraram rupturas que inviabilizaram a implementação da proposta.

Por um lado, a nova gestão do governo do estado de Pernambuco de Eduardo Campos (PSB) decidiu por uma intervenção própria, na esteira da possibilidade de fazer de Recife uma das cidades sede da Copa do Mundo de 2014. O executivo estadual criou, assim, o Núcleo Técnico de Operações Urbanas (NTOU) - responsável por elaborar projetos urbanos de impacto, incluindo a região portuária - e aproximou-se da iniciativa privada para garantir a implementação de tais propostas. O projeto Porto Novo, dessa forma, foi viabilizado a partir do arrendamento da porção não operacional do porto de Recife a um consórcio privado de empresas, que seria responsável pela exploração e gestão do espaço por um prazo determinado (Pernambuco, 2011). Um complexo envolvendo as atividades de lazer, turismo, comércio e negócios foi em parte inaugurado em 2014, ano da Copa, e segue ainda sendo implementado. 
Por outro lado, uma mudança de orientação política do governo federal fez com que a União decidisse leiloar o terreno da extinta Rede Ferroviária Federal (RFFSA), proprietária do Cais José Estelita, apostando em uma negociação direta com investidores privados ${ }^{8}$. A partir disso, um grupo de construtoras e empresas do ramo imobiliário arrematou o espaço do cais no leilão realizado no ano de 2008 e elaborou a proposta do Novo Recife, prevendo a ocupação da área com um empreendimento imobiliário de 13 torres ao longo da linha de frente d'água que estrategicamente conecta os polos turístico, tecnológico, comercial e empresarial da cidade. As repercussões do projeto, a partir de seu lançamento em 2012, desencadearam movimentos contestatórios e de crítica ao projeto, que passou por um conjunto de modificações a partir de então. Ainda assim, o projeto foi viabilizado com base em uma nova legislação urbanística aprovada no Conselho de Desenvolvimento Urbano da cidade (Recife, 2015). Atualmente, com obras em curso, já são divulgados os primeiros imóveis a serem comercializados na área.

\section{As teorias da política urbana e o neoinstitucionalismo}

Os três casos acima discutidos exemplificam não apenas a influência de políticas urbanas globais no Brasil, mas também a relevância da dimensão política necessária à produção de tais intervenções. Nesse contexto, a análise de seu processo de produção adquire particular importância, especialmente à luz da ausência substantiva de estudos deste tipo na sociologia urbana brasileira. Nesse sentido, o debate teórico internacional acerca das políticas do urbano vem buscando articular insights e perspectivas de campos diversos, como a ciência política, a sociologia, a geografia e os estudos urbanos em geral, pelo menos desde meados do século XX.

Nas décadas de 1950 e 1960, teóricos associados à perspectiva norte-americana do "community power", por exemplo, trouxeram a política urbana para o centro de seus estudos e esforçaram-se para explorar a intencionalidade dos agentes na produção das cidades a partir da análise da forma pela qual tais atores moldavam decisões coletivas no plano local (Harding, 2009: 28-29). Assim, a "primeira onda" destes estudos, identificada com a perspectiva teórica elitista, tinha como questão central de investigação "quem dirige/comanda a cidade?" (who runs cities?), pergunta esta que Floyd Hunter (1953) se colocara para o estudo de Atlanta (Harding, 2009: 29-30). Para solucioná-la, o autor realizou uma espécie de "análise de reputação", concluindo que decisões importantes na urbe eram determinadas por um pequeno grupo de formuladores de políticas, os quais, por sua vez, eram dominados por executivos de negócios-chave da cidade. A "segunda onda" de tais investiga-
8. Uma possível razão da mudança de política seria oriunda da crise enfrentada pelo governo federal no episódio do chamado "mensalão", quando ocorreu a mudança no comando do Ministério das Cidades. O ministério até então adotava uma política de defesa da função social dos espaços urbanos. Nesse episódio, o Ministério das Cidades passou do comando de Olivio Dutra (PT), ex-prefeito de Porto Alegre e ex-governador do estado do Rio Grande do Sul, para Márcio Fortes Almeida, indicado pelo PP, partido situado à direita do espectro ideológico no país. 
ções emergiu com o estudo do cientista político Robert Dahl (1961) acerca de New Haven, em 1961. A partir da questão "quem (se alguém) governa New Haven?" (who - if anyone - governs New Haven?), o autor propôs uma "análise de decisão", observando situações particulares de tomada de decisão. A conclusão de Dahl reafirmou a concepção pluralista da democracia, distinguindo-se do enfoque elitista: ninguém governava a cidade em um sentido absoluto. Embora o poder fosse desigualmente compartilhado entre grupos sociais, o estudo de Dahl concluiu que este era suficientemente difuso para impedir o seu controle por uma elite (Dahl, 1961). Embora criticados pela adoção de um certo individualismo metodológico, o debate protagonizado por elitistas e pluralistas, no interior dessa abordagem, trouxe contribuições para o desenvolvimento posterior de pesquisas interessadas nas tomadas de decisões políticas realizadas na escala urbana, e influenciou o desdobramento de novas abordagens nas décadas posteriores. Duas novas linhas teóricas podem ser destacadas: a da "máquina de crescimento", que pode ser entendida como uma abordagem elitista modernizada; e a dos "regimes urbanos", que, por sua vez, apresentava antecedentes pluralistas (Harding, 2009: 33-37).

A abordagem da máquina do crescimento (growth machines) lançou seu olhar para as elites nas cidades, em especial para o grupo social dos promotores imobiliários e sua relação com os governos locais na produção da política urbana (Logan \& Molotch, 1987). O argumento de fundo da abordagem proposta era o de que o desejo por crescimento era uma chave analítica convincente para a compreensão do consenso formado entre as elites locais mobilizadas politicamente no contexto norte-americano de seu tempo. O espírito da máquina de crescimento que penetra as cidades e a maior parte dos aspectos da vida local (o sistema político, a agenda para o desenvolvimento econômico, as organizações culturais etc.), tomaria formas diferentes a depender do período e do contexto estudado. Mas o resultado restaria o mesmo: embora compreendido como benéfico para toda uma localidade, o crescimento teria suas vantagens e desvantagens desigualmente distribuídas na cidade (Logan \& Molotch, 1987: 13).

A abordagem dos regimes urbanos é uma proposta analítica que emerge na literatura anglo-saxã e que se intensificou a partir da década de 1980 (Fainstein \& Fainstein, 1983; Elkin, 1985; Stone, 1989). Ela buscou estudar os modos de colaboração formais e informais entre os agentes dos setores públicos e privados, partindo da perspectiva de que a fragmentação do poder entre tais segmentos exige sua mútua cooperação, a fim de realizarem-se os objetivos políticos locais (Mossberger, 2009: 40). Compreendido como um conjunto de arranjos duradouros entre instituições governamentais e interesses econômicos privados, um regime urbano conduziria à elaboração de políticas urbanas específicas a partir de coalizões formadas por gru- 
pos com algum poder de decisão ou pressão no direcionamento de uma agenda de intervenções na cidade (Stone, 1989). Aqui, o argumento de fundo seria a existência de uma interdependência entre a capacidade de formular políticas, própria das instituições governamentais democráticas, e os recursos de geração de riquezas, pertencentes à economia de mercado (Mossberger, 2009: 41). Dentre os atores que participam de um regime, seria possível distinguir dois tipos de relações: uma relação entre as organizações no núcleo central do regime - na literatura clássica dos regimes urbanos seriam tipicamente o governo local e corporações privadas-chave -, e uma relação entre quem ocupa este núcleo central e quem não ocupa - relação esta que se daria através da distribuição de incentivos seletivos, como, por exemplo, contratações, empregos e facilidades para uma comunidade, além de outros benefícios de pequena escala (Stoker, 2006).

Apesar dos avanços teóricos proporcionados por estas duas correntes, ambas apresentaram limitações e certas dificuldades operacionais. No caso da abordagem da máquina de crescimento, os limites estariam associados à sua adoção em contextos diferentes daquele representado pelo federalismo fiscal norte-americano, onde prevalece maior autonomia dos municípios e investimento privado nas políticas de desenvolvimento local. Além disso, suas conclusões orientadas para a existência de um consenso para o crescimento e de um protagonismo de uma elite específica também foram alvo de críticas (Harding, 2009: 35-36). Já a teoria dos regimes urbanos, em que pese ter ultrapassado fronteiras nacionais, recebeu discordâncias por apresentar componentes pouco flexíveis quanto à identificação dos regimes, na medida em que está associada a estudos de longa duração e na escala da cidade como um todo. A abordagem também foi criticada em razão de sua dificuldade para agregar pautas que prescindissem do desenvolvimento econômico e para identificar como são formados e mantidos regimes que priorizam demandas por justiça social (Mossberger, 2009: 40-41).

A partir dessas considerações, alguns pesquisadores adotaram a noção de governança urbana, compreendida de forma mais ampla e abrangente do que o regime urbano. Sob esta perspectiva, um regime urbano poderia ser entendido e observado como um tipo ou desdobramento desse fenômeno maior e menos limitado (Mossberger, 2009: 47). Ao ascender no grau de abstração e desenvolver um conceito guarda-chuva geral, o conceito de governança urbana seria útil, assim, à apreensão de formas diversas de articulação entre diferentes segmentos na produção da política local, com o incremento de possibilitar ainda a investigação dessas interações em contextos com diferentes graus de autonomia local e sua relação com os fenômenos globais mais amplos (Pierre, 1999). Contudo, embora tenha representado uma relativa descentralização no subcampo teórico das políticas do 
urbano, o conceito de governança, além de ser considerado um tanto polissêmico e normativo (Peters \& Pierre, 2012), acabou associado, principalmente, às pesquisas no ambiente político e institucional europeu.

Desde a década de 1980, ao mesmo tempo em que se intensificava a relevância das abordagens sobre a produção política das cidades, principalmente no contexto norte-americano e europeu, fortalecia-se, em um registro e escopo de abrangência mais amplo nas ciências humanas, a perspectiva neoinstitucionalista. Esta abordagem teórica emergiu a partir de um duplo movimento baseado, por um lado, na crítica à centralidade das instituições formais na análise de políticas e, por outro, na ênfase à importância do contexto institucional em que elas ocorrem. Desta forma, o neoinstitucionalismo mostrou-se atrativo àqueles pesquisadores interessados na compreensão dos processos de formulação e tomada de decisões políticas locais que não necessariamente se encaixavam nas proposições daquelas abordagens mais rígidas, a exemplo da teoria dos regimes urbanos.

De acordo com o neoinstitucionalismo, as instituições constrangem o comportamento e, ao mesmo tempo, são transformadas pela agência (March \& Olsen, 2008). Assim, nas análises dos processos políticos, as convenções e coalizões informais e as regras e estruturas formais que moldam o comportamento político merecem considerável atenção, bem como a maneira pela qual as instituições políticas incorporam valores e relações de poder (Lowndes, 2009: 92). Entretanto, apesar de tal núcleo consensual, o neoinstitucionalismo não constituiu uma corrente de pensamento unificada. De acordo com o esquema classificatório que adquiriu maior influência, três correntes poderiam ser identificadas no neoinstitucionalismo: o da escolha racional, o institucionalismo sociológico e o institucionalismo histórico (Hall \& Taylor, 2003).

Nesse sentido, o institucionalismo histórico seria aquele com maior potencial heurístico, na medida em que marcado por uma mescla entre a perspectiva calculadora, que vê o comportamento como algo estratégico (perspectiva associada ao institucionalismo da escolha racional), e a perspectiva cultural, que salienta o papel da visão de mundo na adoção de determinado comportamento (associada ao institucionalismo sociológico). Assim, a vida política seria influenciada pelas instituições, mas também por outros fatores, como o desenvolvimento socioeconômico e a difusão das ideias na sociedade. Esta abordagem também permitiria analisar o conflito entre grupos rivais pela apropriação de recursos escassos na dinâmica política, ou seja, possibilitaria avaliar questões como a distribuição desigual de poder e de recursos distintos entre os diferentes atores e grupos sociais que constituem os fenômenos sociais (Hall \& Taylor, 2003). 
Um elemento importante da vertente histórica do institucionalismo consiste justamente em seu enfoque temporal, com vistas a compreender trajetórias, sequências e processos que levam a um resultado específico (Pierson \& Skocpol, 2008). Neste caso, as instituições aparecem como produtos desenvolvidos a partir de lutas entre atores desiguais em termos de poder e acesso a recursos. Assim, demandas políticas e políticas públicas são estruturadas por densas interações entre atores econômicos, sociais e políticos, que trabalham de acordo com diferentes lógicas em diferentes contextos. Tais interações, a seu turno, são moldadas por atores coletivos e instituições que "suportam traços de sua própria história" (Immergut, 1998: 17, tradução livre). Nesse contexto, na análise social busca-se demonstrar que as situações políticas são complexas, geralmente envolvendo um leque de variáveis que interagem de diferentes formas entre si (Thelen \& Steinmo, 1992).

No âmbito da complexidade e da historicidade que marcam esta abordagem, ganham especial destaque as noções de "dependência da trajetória" (path dependence) e de "conjuntura crítica" (critical juncture). A dependência da trajetória demonstra que, uma vez estabelecidas as regras do jogo institucionais e as formas gerais de pensar no mundo político, frequentemente serão geradas dinâmicas de retroalimentação (Pierson, 2000; Pierson \& Skocpol, 2008). Em tais processos, as conjunturas críticas seriam aqueles momentos em que mudanças de maior impacto tornam-se possíveis, e em que as respectivas decisões tomadas acabam por influenciar os acontecimentos posteriores. Isto é, a conjuntura crítica introduz um processo de mudança que deixa um legado aos atores envolvidos na tomada de decisões políticas (Capoccia \& Kelemen, 2007; Sorensen, 2014).

Deste modo, no que toca às políticas urbanas em específico, e aos agentes que as produzem, a abordagem neoinstitucional traria contribuições na medida em que se assume que

os jogadores dentro do "jogo" da governança urbana são diversos e incluem organizações (a autoridade local eleita, outras agências de serviços, partidos políticos, organizações voluntárias) e indivíduos (políticos, burocratas, profissionais de serviços, ativistas comunitários, eleitores). [...] As instituições da política urbana não podem, assim, ser reduzidas à organização específica da autoridade local eleita. A formulação da política urbana e a entrega de serviços envolvem hoje atores privados e voluntários, assim como atores do setor público; parcerias e redes são tão importantes quanto relações hierárquicas intraorganizacionais (Lowndes, 2009: 94, tradução livre).

Em sua variante histórica, os estudos urbanos neoinstitucionalistas permitiriam um enfoque profícuo à análise acerca de como padrões de desenvolvimento socioe- 
9. O detalhamento do modelo e de sua construção e operacionalização pode ser consultado em Mariana Vivian (2019). conômicos e políticos são estabelecidos, lançando luz para a persistência de determinadas estruturas sociais e assimetrias de poder no contexto local (Davies \& Trounstine, 2012: 59). Os arranjos institucionais estáveis em cada localidade, nesta perspectiva, são considerados à luz dos diferentes legados históricos das políticas locais (Sorensen, 2014). No processo de formulação de políticas, atores urbanos, impulsionados por uma racionalidade estratégica ou por modelos culturais, interagem em relações que podem ser formalizadas ou não e imbuídos de interesses e visões de mundo (ou de cidades) que se aproximam ou se distanciam.

\section{Intervenções urbanas no Brasil a partir de uma sociologia política}

Viu-se até aqui que as políticas de WR são entendidas como fenômeno contemporâneo de alcance global com repercussões nas cidades brasileiras, as quais, por meio do emprego de diferentes configurações políticas, têm buscado promover transformações de impacto em suas áreas e regiões portuárias não mais operacionais. Nesse contexto, a partir da discussão teórica realizada, a abordagem neoinstitucional, de forma geral, e, especificamente, aquela de orientação histórica, é a abordagem que fornece maior potencial heurístico para o fim de compreender como são construídas e viabilizadas tais políticas no Brasil.

A investigação empírica relativa ao problema de pesquisa foi operacionalizada a partir da elaboração de um modelo sociológico de análise ${ }^{9}$ que se ampara nestes referenciais e distingue as seguintes dimensões analíticas:

i. a dimensão dos atores, que visa identificar a composição dos atores coletivos envolvidos em tais processos, seus objetivos e interesses, e suas visões de mundo - isto é, os conteúdos cognitivos e valorativos que sustentam suas propostas;

ii. a dimensão do procedimento, com o objetivo de observar os respectivos modelos jurídico-administrativos em que operam tais processos - isto é, quais as alternativas escolhidas, dentre as possibilidades legais existentes, para enquadrar a condução formal de cada um dos processos -, a trajetória destes processos, e os momentos-chave de tomada de decisão;

iii. a dimensão dos recursos, com vistas a verificar os instrumentos jurídicos e legislativos - e os incentivos formais e informais - políticos, econômicos, legais, entre outros - de que os atores envolvidos fazem uso; 
iv. a dimensão dos arranjos, com o propósito de definir o desenho de relação formal e informal, e as regras do jogo criadas ou resgatadas no curso de tais processos; e

v. a dimensão do contexto sócio-histórico, que visa considerar as situações socioeconômicas, espaciais, histórica e políticas presentes.

À luz dos debates teóricos e das realidades empíricas apresentados, entende-se que tal quadro analítico tem o potencial de contribuir para uma sociologia política de intervenções urbanas de alta complexidade. No caso das políticas brasileiras de WR estudadas, os resultados analíticos associados ao modelo são sintetizados a seguir.

Análise dos casos:

uma sintese

Uma síntese dos resultados produzidos revelou que matizes comuns perpassam todos os processos institucionais analisados, embora tenham resultado em apropriações e criações diversas de políticas de WR. Nesses processos, como se verá, as relações contextuais que permeiam a realidade das cidades parecem ser determinantes para a eleição de determinados procedimentos, assim como para a participação em diferentes graus de atores e grupos sociais específicos, elementos estes que, a seu turno, parecem influenciar a organização de arranjos e a mobilização de recursos particulares, de forma a garantir as transformações almejadas. Este enquadramento geral é apresentado na sequência, a partir de cada uma das dimensões de análise.

\section{Dimensão dos atores sociais}

Os principais grupos e atores sociais envolvidos nos processos de "revitalização" das áreas portuárias em questão são as administrações públicas, das três esferas da Federação, com destaque para as respectivas esferas municipal e/ou estadual, além de atores do mercado, representados pela formação de consórcios empresariais de áreas diversas. Tais consórcios são, em grande medida, representativos do grupo de atores que têm seus processos de acumulação relacionados à valorização do espaço urbano, como empreendedores imobiliários, grupos financeiros, empreiteiras etc. Entram em cena, ainda, atores públicos e privados específicos que veem nesses processos de intervenção urbana oportunidades de investimento e rentabilização financeira, como fundos de investimentos e agências financeiras ${ }^{10}$.

Na esfera da chamada sociedade civil ou dos atores civis, a investigação demonstrou que sua participação em tais processos é episódica, e, por vezes, fragmentada.
10. Cabe destacar que participam também, em menor grau, os Poderes Legislativos Municipais e, por vezes, o Poder Judiciário, acionado por aqueles que contestam as propostas oficiais, além de órgãos de controle e agências nacionais reguladoras quando diretamente envolvidas. Há ainda a atuação dos Conselhos Municipais dos Plano Diretores, dotados do poder de analisar os projetos de intervenção urbana. Ganha destaque também a criação de agências com o propósito específico de conduzir as "revitalizações" planejadas e aprovadas. 
O debate público acerca das alternativas para a "revitalização" dos respectivos territórios mostra-se limitado, na medida em que somente ocorre após as propostas já estarem delineadas pelos agentes promotores das respectivas intervenções, em especial as administrações municipais - evidenciando, assim, a ausência de espaços participativos com poder deliberativo em suas formulações.

Os interesses e objetivos em jogo na produção das políticas estudadas envolvem principalmente a mudança no uso do solo para a criação de valor a partir do espaço transformado - que pode ser mais ou menos distribuído - e para a criação de novas imagens urbanas de "sucesso" associadas a gestões políticas específicas. Nesse sentido, as propostas interventivas são amparadas por visões de mundo que concebem a cidade ideal como aquela que promove "crescimento" e que se apresenta como multidimensionalmente atrativa frente às demais - turística, estética, imobiliária e mercadológica. Além disso, a produção de políticas urbanas indutoras de crescimento e atratividade é vista como tarefa para a qual o segmento público detém pouca capacidade, devendo ser promovida através da delegação ou do estabelecimento de parcerias com o setor privado.

A produção das "revitalizações" nos moldes em que estão dadas é justificada pelos legados que promovem, incluindo a possibilidade de ocupação de espaços representados como degradados e abandonados, o desenvolvimento imobiliário das respectivas localidades em que estão situados, a geração de empregos com as obras, os serviços e os equipamentos a serem instalados, a preservação de ícones históricos e culturais, as melhorias sociais associadas à implementação dos projetos, dentre outros.

\section{Dimensão do procedimento}

Tais processos são caracterizados por diferentes procedimentos jurídico-administrativos de modelagem da política, em razão de fatores contextuais particulares. Tais modelos, contudo, mesmo que formalmente diversos, compartilham da característica fundamental da cessão de determinadas prerrogativas para os grupos privados envolvidos, que podem ser de ordem regulatória, exploratória e/ou de prestações de serviços, e são baseados no adensamento construtivo dos espaços e na valorização do solo - valorização esta que resulta não apenas da intensificação do uso da terra, mas também de seu crescimento por modernas infraestruturas e construções de alto padrão. A mais-valia urbana gerada com tais políticas é mais ou menos apropriada por tais atores, a depender da modelagem jurídico-administrativa formal adotada. 
No todo, tais trajetórias podem ser genericamente identificadas a partir de quatro fases distintas: uma primeira fase, em que se consolida politicamente a decisão de intervir ${ }^{11}$; uma segunda fase em que há a demarcação de diretrizes básicas para a intervenção ${ }^{12}$; uma terceira fase de aprimoramento e definição do modelo de intervenção ${ }^{13}$; e, por fim, uma quarta fase, caracterizada pelo início dos trâmites de estudos e licenciamentos necessários à execução das intervenções, além de outros desdobramentos específicos a cada caso.

Assim, os momentos-chave de tais processos institucionais são marcados inicialmente pelos lançamentos das primeiras propostas interventivas para as áreas em questão, colocando o tema da "revitalização" nas agendas públicas e privadas de cada localidade. Em seguida, destacam-se momentos em que, com o ingresso de novos atores políticos nas gestões municipais e/ou estaduais, são tomadas decisões que reservam aos projetos interventivos um lugar prioritário nas respectivas agendas de governo e que, em consequência, garantem avanços formais e informais a cada proposta. Tais avanços são logrados em diferentes graus e direções, a depender da presença ou ausência de alinhamento político para revitalizar em cada caso.

Na sequência, destacam-se momentos-chave de tomada de decisão em que são realizadas maiores aproximações público-privadas com o fim de garantir a viabilidade da implementação, nas quais são negociados os parâmetros definidores das políticas de "revitalização". Estes momentos são especialmente relevantes, pois são os momentos em que são decididos quais serão os projetos implementados, assim como suas diretrizes. Estes ocorrem, em todos os casos, antes dos respectivos procedimentos licitatórios ou da publicização dos debates, por força da eleição de determinadas estratégias procedimentais pelas administrações públicas na maior parte dos $\operatorname{casos}^{14}$. No conjunto de tomadas de decisões dos respectivos processos, estas parecem ser aquelas que instauram marcos de difícil mudança quando estabelecidos, na medida em que demarcam os quadros de referência das políticas adotadas, dentro das quais qualquer mudança de direção se mostra politicamente custosa.

Nas trajetórias de tais processos, portanto, a sequência de atos e decisões em direção às respectivas "revitalizações" assume um papel central para o desencadear de resultados específicos. Nesse sentido, os três casos estudados apresentam momentos que expressam o poder que determinadas decisões tomadas exercem sobre as decisões seguintes, limitando paulatinamente a amplitude do debate em torno das intervenções. Se as discussões consideradas técnicas parecem incorporar um leque de atores coletivos, o mesmo não pode ser dito em relação às discussões políticas, desenvolvidas em um núcleo específico e bastante restrito de agentes. As publicizações das propostas mostram-se importantes para o ativismo contestatório
11. Nesta fase, percebe-se: a circulação internacional de ideias envolvendo as políticas de WR como modelo urbano de sucesso, a criação de imaginários locais favoráveis a tais modelos interventivos, as primeiras proposições públicas e privadas para as áreas, e as tentativas de estabelecimento de consensos políticos para o fim de intervir.

12. Em geral, nesta fase ocorrem os atos públicos que formalizam a participação de agentes privados do mercado imobiliário e financeiro nas intervenções e que estabelecem o grupo de atores públicos que irão analisar e negociar a partir das propostas dos agentes privados.

13. Esta fase representa o período em que se garantem os modelos negociados por meio da elaboração de editais, da formulação de projetos de lei e de acordos que podem ser formalizados em contratos ou não, entre outros.

14. Tais estratégias se dão através do uso dos mecanismos legais existentes que possibilitam esse tipo de ação, como procedimentos de Manifestação de Interesse - em que as 
propostas privadas selecionadas e analisadas efetivamente contribuem na definição do conteúdo dos editais publicados e das políticas lançadas posteriormente ou procedimentos burocráticos que permitem a demarcação conjunta de diretrizes para os empreendimentos. aos modelos de cima para baixo, mas ocorrem apenas após a tomada de decisões fundamentais, fornecendo poucas alternativas de discussão pública dos usos possíveis do espaço.

\section{Dimensão dos recursos}

Esses processos também são marcados pela mobilização de instrumentais jurídicos e legislativos, os quais, ainda que formalmente diversos, cumprem, na prática, uma mesma função, em maior ou menor grau, de produção de novas normas para o espaço que garantam as transformações almejadas. Tais instrumentos servem ao propósito geral de assegurar o financiamento, a agilidade, a autonomia, a viabilidade econômica e a legitimação das políticas concebidas. Nesse sentido, são produzidas flexibilizações regulatórias, através de criações ou manipulações das normas formais, que operam como incentivo aos investidores. Estes instrumentos mobilizados contribuem para o adensamento e a valorização do solo e de seu entorno, produzindo espaços diferenciados do restante das cidades.

A mobilização de recursos financeiros também influencia no curso de tais processos, sendo operacionalizada em diferentes graus de complexidade em cada caso. Em termos econômicos, desta forma, os incentivos mobilizados são, em regra, direcionados aos grupos privados envolvidos, embora existam outros percursos e atores para os quais estes são orientados. Tais incentivos abrangem a criação de novos espaços urbanos com maior permissividade exploratória, o poder de negociação imobiliária nesses espaços, a transferência da prestação de serviços públicos, a lucratividade dos investimentos e o pagamento de contraprestações.

Ademais, a produção de um imaginário de "modernização" e de crescimento econômico e urbano opera como incentivo político, na medida em que garante, às respectivas administrações, produtos concretos de suas gestões no quadro da competição eleitoral. Por fim, todos os processos são assinalados pela mobilização de incentivos sociais diversos, tais como as chamadas contrapartidas que, mesmo que acessórias em relação aos demais, visam garantir a aprovação e a legitimidade dos projetos frente às populações locais.

\section{Dimensão dos arranjos}

Os arranjos institucionais adotados na produção das "revitalizações" têm em comum a associação entre as respectivas administrações públicas e os grupos empresariais, ainda que os desenhos formais dessa relação sejam diversos e possam envolver outros atores. As relações de poder entre os atores envolvidos, eviden- 
ciadas, em grande parte, pelos recursos de que dispõem, mostram-se desiguais: os consórcios empresariais dispõem de posição privilegiada, pois contam com recursos técnicos e econômicos de que podem lançar mão; as administrações públicas detêm o poder de mobilizar instrumentais jurídicos e legislativos (poder político-estatal) para atender os objetivos traçados; e os setores sociais não estatais e que não pertencem aos grupos de interesse deste mercado são os mais desprivilegiados nessas relações, fazendo uso do Poder Judiciário e de alguns espaços políticos quando intentam contestar os respectivos processos no plano institucional formal.

No interior das administrações públicas, cumprem um papel fundamental determinados atores-chave selecionados para o fim de levar as políticas adiante em cada caso. Nesse sentido, o estabelecimento de agências mediadoras, sejam essas uma instituição, um agente individual ou um setor específico da administração pública, também fortalecem os arranjos estabelecidos para o fim de intervir ${ }^{15}$. Ademais, o suporte de outras instituições envolvidas com as transformações e o apoio do poder legislativo também cumprem funções de relevo nesses processos.

As regras do jogo que são criadas ou resgatadas através desses arranjos, em última análise, conduzem a uma estrutura de oportunidades e restrições desiguais entre os atores, de forma a reforçar relações de poder político previamente existentes entre os atores. O segmento privado envolvido logra, na maioria dos casos, uma redução dos riscos próprios às intervenções, em uma cadeia de tomada de decisões que paulatinamente limitam o debate político sobre estas. As regras adotadas promovem a transferência de prerrogativas públicas, incluindo a própria formulação dos projetos, que, na prática, é, em grande medida pautada pelos atores privados envolvidos. A distribuição de competências alocadas nesses arranjos parece ainda garantir a tais atores privados um amplo conjunto de poderes para a produção das projeções. Às administrações públicas resta um papel formal de fiscalização e, em certa medida, um papel informal de facilitação das intervenções nos termos acordados. Tais agentes imbricam-se, desta forma, em relações público-privadas que reproduzem uma associação característica da sociedade brasileira e que, na escala local, mostram-se mais assimétricas em termos de poderes decisórios.

No conjunto dos processos institucionais estudados, portanto, é notável a predominância de mandatos públicos e segmentos privados diversos (construção civil, imobiliário, financeiro) com objetivos e visões de mundo passíveis de coordenação, que optam por modelos interventivos baseados na transferência de prerrogativas e na valorização do solo. Tais modelos são negociados em circuitos fechados anteriores à publicização das intervenções. Nesses processos, ainda, criam-se ou manipulam-se normas para a garantia dos modelos interventivos acordados, com distribuição
15. O desempenho deste papel demonstra que, em algumas situações, o lócus governamental garantidor das intervenções está menos em um local específico das burocracias estatais do que em atores com expertise e confiança política com a incumbência de levar a cabo as políticas de "revitalização". Para tal, é relevante o trânsito que dispõem nos meandros da administração pública e nas relações com os agentes privados 
16. A realização das conferências nacionais das cidades e a criação do Conselho Nacional das Cidades, vinculado ao Ministério das Cidades, surgido em 2003, no início do governo Lula, representou o ápice da participação nas políticas urbanas do país.

\section{Estes}

últimos foram

emblematicamente representados pela realização no país dos megaeventos esportivos: a Copa do Mundo de Futebol, em 2014, e as Olimpíadas, em 2016.

18. No Brasil, após redemocratização, ocorreu a expansão de espaços institucionais de participação social nas três esferas de governo. Juntamente com os conselhos de políticas públicas, a inovação mais notória foi a do Orçamento Participativo (OP). O seu caráter inclusivo está associado ao atendimento das carências básicas de acesso à infraestrutura urbana e serviços. Todavia, são poucos os casos de efetiva incidência nas prioridades orçamentárias. Além disso, pesquisas recentes indicam o declínio do número de OPs no país. de incentivos de ordem econômica, política e social, por meio de arranjos que envolvem certa associação público-privada baseada em consensos decisórios, com ampliação da margem de atuação privada sobre a formulação das políticas.

\section{Dimensão do contexto sócio-histórico}

O contexto histórico do Brasil associado aos casos de WR em questão é marcado por décadas de crescimento urbano acelerado conjugado com a seletividade do investimento público em bens e serviços em determinadas áreas e regiões intraurbanas. À exclusão e à fragmentação social da urbanização brasileira daí decorrentes, já há muito conhecidas, soma-se a pouca atenção atribuída aos espaços públicos urbanos e às mudanças macroeconômicas a partir dos anos 1980, que, como discutido, determinaram a obsolescência de certas áreas portuárias situadas nas regiões centrais das cidades.

Não obstante o surgimento inovador de políticas urbanas em níveis nacional e local, na esteira da Constituição de 1988, cujo marco é o Estatuto da Cidade, a construção institucional dos projetos de intervenção em questão ocorreu em um contexto político e socioeconômico relativamente paradoxal. Por um lado, o crescimento econômico do país nos anos 2000 foi acompanhado de redução dos recursos federativos para os municípios, criando um quadro fiscal de escassez local para o investimento público em projetos de grande porte. Essa escassez abriu oportunidades para as políticas de cessão de equipamentos, áreas urbanas e serviços aos agentes do mercado. Por outro lado, as mudanças do contexto político nacional na década citada favoreceram a construção de consensos políticos inéditos. Assim, alianças e arranjos institucionais tornaram-se possíveis também porque a contestação político-partidária foi reduzida, comparativamente à contestação social e ambiental. Este caráter paradoxal na esfera federal é representado tanto pela ampliação da participação institucional na política urbana ${ }^{16}$, quanto pelo fortalecimento do city marketing e do empreendedorismo urbano conectados ao processo de globalização ${ }^{17}$.

No plano local, esses traços se manifestariam em uma experiência democrática com práticas pontuais de efetiva decisão popular na formulação de políticas para a urbe $^{18}$ e com uma desigual distribuição de poder entre os atores nas cidades (Santos Junior \& Montandon, 2011). Além disso, nos casos em estudo, as especificidades conjunturais de cada localidade garantiriam diferenciais de relevo no modo como as propostas foram viabilizadas. O caso da operação urbana no Rio de Janeiro é bastante ilustrativo, pois somente parece ter sido possível, nos moldes em que foi implementada, graças a um contexto muito específico da cidade no momento 
de sua instauração. Enquanto os casos de Recife e Porto Alegre representam dinâmicas mais tradicionais e menos complexas de interação público-privada, no Rio de Janeiro o Porto Maravilha retratou uma operação, rapidamente desenvolvida e posta em prática, envolvendo uma PPP de grande magnitude e com a delegação de um conjunto de serviços públicos, financiada em grande medida por uma única agência federal estatal, em um arranjo financeiro e institucional complexo e inovador. Além de um contexto de pujança econômica, a cidade vivia um alinhamento político entre os três entes federados, nunca experimentado, e a conviç̧ão compartilhada de sediar os Jogos Olímpicos de 2016.

\section{Considerações finais}

O presente estudo buscou investigar os processos institucionais de construção dos projetos de WR em três importantes cidades brasileiras. A síntese dos resultados indica, de forma geral, que em todas um mesmo modelo de intervenção pôde ser observado, o qual se ampara na concessão de áreas públicas centrais, estratégicas e simbólicas, para exploração privada para fins diversos. Os processos institucionais que viabilizam, ou buscam viabilizar, tais políticas, por sua vez, são marcados por nuances específicas, em cada um dos casos, por se tratar de políticas que comportam modelagens jurídico-políticas próprias, realizadas em diferentes contextos locais, e que abrangem escalas distintas. Ao mesmo tempo, tais processos apresentam dinâmicas que se assemelham em muitos aspectos e que, de alguma forma, parecem indicar práticas compartilhadas pelos agentes promotores de tais políticas no Brasil. Desta forma, a despeito das particularidades de cada um dos casos, um enquadramento geral das políticas de WR no Brasil pode ser identificado, fornecendo uma chave de leitura comum aos processos institucionais de produção de "revitalizações" urbanas estudados.

\section{Referências}

ARANTES, Otília Beatriz F. Uma estratégia fatal: a cultura nas novas gestões urbanas. In: ARANTES, O.; VAINER, C.; MARICATO, E. (Orgs.). A cidade do pensamento único: desmanchando consensos. 3. ed. Petrópolis, RJ: Vozes, 2002.

BASSETT, Keith; GRIFFITHS, Ron; SMITH, Ian. Testing governance: partnerships, planning and conflict in waterfront regeneration. Urban Studies, v. 39, n. 10, p. 1757-1775, 2002. 
BRASIL. Projeto urbanístico Recife-Olinda. 2006. Disponível em: < https://www.mdr. gov.br/images/stories/ArquivosSNPU/Biblioteca/ReabilitacaoAreasUrbanas/Biblioteca_Projeto_Urbanistico_Recife-Olinda.pdf>. Acesso em: 29 jul. 2020.

. Reabilitação de centros urbanos. Brasília: Ministério das Cidades. 2005. Lei n. 10.257, de 10 de julho de 2001.

CAPOCCIA, Giovanni; KELEMEN, R. Daniel. The study of critical junctures: theory, narrative, and counterfactuals in historical institutionalism. World Politics, v. 59, n. 3, p. 341-369, 2007.

DAHL, Robert. Who governs? New Haven,CT: Yale University Press, 1961.

DAVIES, Jonathan S.; TROUNSTINE, Jessica. Urban politics and the new institutionalism. In: JOHN, P.; MOSSBERGER, K.; CLARKE, S. E. (Eds.). The Oxford handbook of urban politics. Oxford handbooks online. Oxford, UK: Oxford University Press, 2012.

ELKIN, Stephen. Twenty century urban regimes. Journal of Urban Affairs, n. 5, p. 11-27, 1985.

FAINSTEIN, Norman; FAINSTEIN, Susan. Regimes strategies, communal resistance and economic forces. In: FAINSTEIN, N.; FAINSTEIN, S. (Eds.). Reestructuring the city. New York: Longman, 1983.

GARCIA, Fernanda E. Sanchez. Cidade espetáculo: política, planejamento e city marketing. Curitiba: Palavra, 1997.

GONÇALVES, Rafael S. Grandes eventos e renovação urbana do Rio de Janeiro em uma perspectiva histórica. In: . (Org.). Pobreza e desigualdade social: ontem e hoje. Rio de Janeiro: Letra Capital, 2013.

GOVERNO DO ESTADO DO RIO GRANDE DO SUL. Governo abre o 20 envelope do processo de revitalização do Cais Mauá nesta sexta-feira. 2010. Disponível em: <https://www.estado.rs.gov.br/governo-abre-o-2-envelope-do-processo-de-revitalizacao-do-cais-maua-nesta-sexta-feira>. Acesso em: 22 Abr. 2020.

HALL, Peter; TAYLOR, Rosemary. As três versões do neo-institucionalismo. Lua Nova, n. 58, p. 193-223, 2003.

HARDING, Alan. The history of community power. In: DAVIES, J.; IMBROSCIO, D. (Ed.). Theories of urban politics. 2. ed. Los Angeles,CA: Sage, 2009.

HARVEY, David. A produção capitalista do espaço. São Paulo: Annablume, 2005. 
HOYLE, Brian. Global and local change on the port-city waterfront. The Geographical Review, v. 90, n. 3, p. 395-417, 2000.

HUNTER, Floyd. Community power structure: a study of decision makers. Chapel Hill, NC: The University Of North Carolina Press, 1953.

IMMERGUT, Ellen M. The theoretical core of the new institutionalism. Politics \& Society, Sage Publications, v. 26, n. 1, p. 5-34, 1998.

LOGAN, John; MOLOTCH, Harvey. Urban fortunes: the political economy of place. Berkeley, CA: University Of California Press, 1987.

LOWNDES, Vivien. New institutionalism and urban politics. In: DAVIES, J.; IMBROSCIO, D. (Eds.). Theories of urban politics. 2. ed. Los Angeles, CA: Sage, 2009.

MARCH, James G.; OLSEN, Johan P.. Neo-institucionalismo: fatores organizacionais na vida política. Revista de Sociologia e Política, v. 16, n. 31, p. 121-142, 2008.

MOSSBERGER, Karen. Urban regime analysis. In: DAVIES, J.; IMBROSCIO, D. Theories of urban politics. 2. ed. Los Angeles, CA: Sage, 2009.

PERNAMBUCO. Edital de concorrência pública porto do Recife n. 007/2011, de novembro de 2011.

PETERS, Guy; PIERRE, Jon. Urban governance. In: JOHN, P.; MOSSBERGER, K.; CLARKE, S. (Eds.). The Oxford handbook of urban politics. Oxford handbooks online. Oxford, UK: Oxford University Press, 2012.

PIERRE, Jon. Models of urban governance: the institutional dimension of urban politics. Urban Affairs Review, Sage Publications, v. 34, n. 3, p. 372-396, 1999.

PIERSON, Paul. Increasing returns, path dependence, and the study of politics. American Political Science Review, v. 94, n. 2, p. 251-267, 2000.

PIERSON, Paul; SKOCPOL, Theda. El institucionalismo histórico en la ciencia política contemporánea. Revista Uruguaya de Ciencia Política, v. 17, n. 1, p. 7-38, 2008.

PORTO ALEGRE. Lei Complementar n. 638, de 04 de março de 2010.

RECIFE. Lei Municipal n. 18.138, de 04 de maio de 2015.

RIBEIRO, Luiz C. Q. A metrópole em questão: desafios da transição urbana. 2. ed. Rio de Janeiro: Letra Capital, 2018.

RIO DE JANEIRO. Concorrência Pública n. 001/2010 - AEIU da Região Portuária do Rio de Janeiro, 2010. 
. Decreto n. 30.355, de 01 de janeiro de 2009a.

. Lei Complementar n. 101, de 23 de novembro de 2009b.

Lei Complementar n. 102, de 23 de novembro de 2009c.

Lei Complementar n. 105, de 22 de dezembro de 2009d.

. Diário Oficial do Município do Rio de Janeiro, Ano XXI, n. 192, 02 Jan. 2008. Decreto n. 26.852, de 08 de agosto de 2006.

RIO GRANDE DO SUL. Edital de Concorrência n. 01/2010, de 8 de julho de 2010.

. Decreto Estadual n. 45.187, de 27 de julho de 2007.

ROBERTS, Peter. The evolution, definition and purpose of urban regeneration. In: ROBERTS, P.; SYKES, H. (EdS.). Urban regeneration: a handbook. Los Angeles, CA: Sage, 2000.

SANTOS JUNIOR, Orlando A.; MONTANDON, Daniel T. (Orgs.). Os planos diretores municipais pós-estatuto da cidade: balanço crítico e perspectivas. Rio de Janeiro: Letra Capital, 2011.

SMITH, Neil. A gentrificação generalizada. In: BIDOU-ZACHARIASEN, C. (Org.). De volta à cidade: dos processos de gentrificação às políticas de "revitalização" dos centros urbanos. São Paulo: Annablume, 2006.

SORENSEN, André. Taking path dependence seriously: an historical institutionalist research agenda in planning history. Planning Perspectives, v. 30, n. 1, p. 17-38, 2014.

STOKER, Gerry. Comparative local governance. In: RHODES, R. W.; BINDER, S. A.; ROCKMAN, B. A. (Eds.). The Oxford handbook of political institutions. New York: Oxford University Press, 2006.

STONE, Clarence. Regime politics: governing Atlanta, 1946-1988. Lawrence, KS: University Press of Kansas, 1989.

THELEN, Kathleen; STEINMO, Sven. Historical institucionalism in comparative politics. In: STEINMO, S.; THELEN, K.; LONGSTRETH, F. (EdS.). Structuring politics: historical institucionalism in comparative analysis. Cambridge, UK: Cambridge University Press, 1992. 
VAINER, Carlos. Pátria, empresa e mercadoria: Notas sobre a estratégia discursiva do Planejamento Estratégico Urbano. In: ARANTES, O.; VAINER, C.; MARICATO, E. A cidade do pensamento único: desmanchando consensos. 3. ed. Petrópolis, RJ: Vozes, 2002.

VIVIAN, Mariana M. Transformações urbanas no século XXI: trajetórias e produção institucional das políticas de waterfront regeneration no Brasil. Dissertação (Mestrado em Sociologia) - Programa de Pós-Graduação em Sociologia, Universidade Federal do Rio Grande do Sul, Porto Alegre, 2019.

YIN, Robert K. Estudo de caso: planejamento e métodos. 2. ed. Porto Alegre: Bookman, 2001. 